Vol 11, Issue 7, 2018

\title{
EVALUATION OF ANTHELMINTIC ACTIVITY OF MOMORDICA CHARANTIA, CUCURBITA PEPO L., AND SOLANUM TORVUM BASED FORMULATION AND ITS PHYTOCHEMICAL ANALYSIS USING FOURIER TRANSFORM INFRARED
}

\author{
JANNATHUL FIRDOUS ${ }^{1}$, BHARATHI $V^{2 *}$, NOORZAID MUHAMAD ${ }^{1,3}$ \\ ${ }^{1}$ Department of Preclinical, Faculty of Medicine, Universiti Kuala Lumpur Royal College of Medicine Perak, No.3, Jalan Greentown, \\ 30450, Ipoh, Perak, Malaysia. ${ }^{2}$ Department of Biochemistry, Shrimati Indira Gandhi College, Tiruchirappalli, Tamil Nadu, India. ${ }^{3}$ Student \\ Development Division, Universiti Kuala Lumpur Royal College of Medicine Perak, Jalan Greentown, 30450 Ipoh, Perak, Malaysia. \\ Email: bharathi2679@gmail.com \\ Received: 09 March 2018, Revised and Accepted: 16 April 2018
}

ABSTRACT

Objective: In the present study, the phytochemical and anthelmintic effect of a formulation (MCS) prepared from the plants, namely Momordica charantia, Cucurbita pepo L., and Solanum torvum were investigated.

Methods: Phytochemical constituents were analyzed using Fourier transform infrared (FTIR), and anthelmintic activity of methanolic and aqueous extract MCS formulation against earthworm Pheretima posthuma was evaluated.

Result: As a result of FTIR analysis, MCS formulation showed the presence of coumarin, flavonoids, tannin, phenolic compound, saponin, quinone, and alkaloids. In investigating the anthelmintic action of formulation against adult Indian earthworms, the values of paralytic time and death time of formulation were less when compared to the positive control albendazole.

Conclusion: The present work concludes that the MCS formulation acts as a more suitable herbal treatment against helminths infection.

Keywords: Anthelmintic action, Fourier transform infrared, Gastrointestinal parasites, Livestock, Phytochemicals.

(c) 2018 The Authors. Published by Innovare Academic Sciences Pvt Ltd. This is an open access article under the CC BY license (http://creativecommons. org/licenses/by/4. 0/) DOI: http://dx.doi.org/10.22159/ajpcr.2018.v11i7.25806

\section{INTRODUCTION}

Gastrointestinal (GI) parasites are major constraints to livestock production and also affecting human population worldwide. As estimated, 3.5 billion people were infected by intestinal nematodes in both developing and developed countries [1]. Helminthiasis is the most common infections in humans, affecting more people around the world. The worms infecting the GI tract can also protrude into other organs including the liver and can cause severe blood loss by their toxins secretion [2]. Helminths are also considered to be a major health issue in livestock production where helminth infections of domesticated animals cause sub-clinical diseases and economic losses. Helminth infections are even chronic that causes morbidity among human and animals than other group of parasites [3]. Controlling helminths over anthelmintic drugs are expensive, and the large-scale usage of such drugs lead to the emergence of multiple anthelmintic resistances [4]. These factors demand for alternative and environmentally innocuous control methods like natural herbal remedies. Worldwide, medicinal plants are evaluated for their anthelmintic property and used for treatment as anti-parasitic agent [5]. Therefore, studies on herbs were focused thereby extracting phytochemicals rich in anthelmintic property.

The use of plant compounds such as phytochemicals is of interest in therapeutic facilities and plant compounds are used in traditional medicinal system in the treatment of infectious disease [6]. Previous studies on various plant compounds were conducted all around the world and hence proved their potential activity against parasites [7]. Phytochemicals are reported for antiplasmodial, anti-inflammatory, hepatoprotective, anticancer, and antioxidant activity. Further, the phytochemical tannin is known for anthelmintic activity which impairs different biological Key processes of the parasitic nematode life cycle [8]. Analysis of such phytochemicals is based on the extraction from plants by any of the methods which include maceration, infusion, percolation, digestion, decoction, Soxhlet extraction, aqueous-alcoholic extraction by fermentation, counter-current extraction, microwaveassisted extraction, ultrasound extraction, supercritical fluid extraction, and phytonic extraction [9].

Momordica charantia is a common Indian plant, belongs to the family Cucurbitaceae, and is known as bitter melon. It thought to stimulate digestive function and improves appetite. Various parts of $M$. charantia are used to treat diabetes. The extracts of $M$. charantia are found to be pharmacologically active against helminths [10]. Cucurbita pepo L. reported to possess anthelmintic properties where its seed extract used to expel tapeworms. Its secondary metabolites such as cucurbitacin B, cucurbitin, cucurmosin, saponins, and sterols are involved in affecting GI nematodes [11]. Solanum torvum is another herbal plant with anthelmintic activity [12]. It is also used to treat cold and flu, stomach aches, and gonorrhea. In the present study, the anthelmintic potential of M. charantia, C. pepo L., and S. torvum was assessed, and the phytochemicals present in them were analyzed using Fourier transform infrared (FTIR).

\section{METHODS}

Preparation of plant extract

Seeds of M. charantia, C. pepo L. and S. torvum were collected from the local market, Trichy, Tamil Nadu, India. Dried seeds were ground into a coarse powder. The three seed powders were equally weighed and mixed thoroughly to make the formula MCS. For aqueous extract, $100 \mathrm{~g}$ of powder was taken in a beaker and suspended in $600 \mathrm{ml}$ of water and mixed. For the methanolic extract, $100 \mathrm{~g}$ of powder was added to $500 \mathrm{ml}$ of methanol solvent and mix thoroughly. The filtrates of both extracts were collected through Whatman filter paper No. 4. This 
extract was used for phytochemical analysis and anthelmintic activity. The extract was dried through vacuum rotary evaporator at $20 \mathrm{rpm}$ in a temperature below $40^{\circ} \mathrm{C}$, under reduced pressure. The condensed form of the extract was collected, transferred to an air-tight container and stored in a freezer at $-20^{\circ} \mathrm{C}$ till subsequent use [13].

\section{Preliminary phytochemical analysis}

Preliminary phytochemical analytical tests such as test for saponins, phenols, tannins, terpenoids, and flavonoids for screening the bioactive chemical compounds in the guava were carried out with the aqueous and alcoholic extracts using the standard procedure as described by Tanaka et al. [14]. For each phytochemical test, $1 \mathrm{ml}$ of the mentioned solvent extract was used for analysis.

\section{Phytochemical evaluation}

FTIR spectroscopy was used for the analysis of various functional groups present in the extract which was absorbed at their own characteristic frequencies. The peak values of FTIR were recorded where the band structure and structural geometry of the compound were identified in terms of frequency and intensity of absorption [8]

\section{In vitro anthelmintic activity}

Indian adult earthworms Pheretima posthuma were used to carry out the anthelmintic evaluation. During this study, the earthworms were exposed to methanolic and aqueous based MCS formulation and their survival time was noted to determine the anthelmintic activity of given formulation. Initially, the worms were washed in normal saline solution, and their length was measured. Worms with equal sizes were taken in a Petri plate ( 6 worms/plate), and the formulation was added to the plates at the various concentration such as 10 and $20 \mathrm{mg} / \mathrm{ml}$. Time taken for paralysis and death was observed for individual worm in each plate after ascertaining that the worms neither moved when shaken vigorously nor when dipped in warm water at $50^{\circ} \mathrm{C}$. All the results were expressed as a mean \pm standard error of mean of six worms in each group [15]. Albendazole tablet in powder form $(0.07 \mathrm{w} / \mathrm{v})$ was dissolved in $2 \mathrm{ml}$ of dimethylformamide, and $8 \mathrm{ml}$ of normal saline solution $(9 \% \mathrm{NaCl})$ was used as a positive control.

\section{RESULTS}

\section{Preliminary phytochemical and FTIR analysis}

Primary phytochemical assays revealed the presence of flavonoids, tannins, saponin, alkaloids, quinone, and polyphenolic compounds in MCS formulation. FTIR measurement was also carried out to identify the possible biomolecules responsible for anthelmintic activity. The spectrum showed a lot of absorption band that confirmed the presence of active functional groups in the MCS formulation as shown in Fig. 1.
From Fig. 1, the intensity peaks were slightly increased at 3924/ $\mathrm{cm}, 3790 / \mathrm{cm}, 2256 / \mathrm{cm}$, and $1930 / \mathrm{cm}$ as well as some intensity peaks decreased at $1242 / \mathrm{cm}$ and $1054 / \mathrm{cm}$. Results of FTIR band at $3924 / \mathrm{cm}$ and $3790 / \mathrm{cm}$ corresponded to alcohols and phenols. The peak at $3404 / \mathrm{cm}$ represents to $\mathrm{N}-\mathrm{H}$ stretch indicated the presence of primary, secondary amines, and amides. Similarly, the peaks at $2901 / \mathrm{cm}$ and $2975 / \mathrm{cm}$ showed the presence of alkanes. Presence of aldehydes was noted at peak $2256 / \mathrm{cm}$. The weak band at $438 / \mathrm{cm}$ and 1930/cmindicated C-Br stretch and C-Cl stretch with alkyl halides that correspond to the presence of alcohols, carboxylic, acids, ethers, esters, and aliphatic amines in the plant extract. Other bands at $1758 / \mathrm{cm}$, $1645 / \mathrm{cm}$, and $1242 / \mathrm{cm}$ showed the presence of alkynes and aliphatic amines. The presence of these active functional groups in plant extract was responsible for anthelmintic activity.

\section{In vitro anthelmintic activity}

The formulation exhibited anthelmintic activity in dose-dependent manner with shortest time of paralysis and death was noted in both extracts of formulation at $20 \mathrm{mg} / \mathrm{ml}$ concentration. Both the extracts showed improved anthelmintic activity at $20 \mathrm{mg} / \mathrm{ml}$ as shown in Table 1.

Higher concentration of extract produced paralytic effect much earlier and the time taken for death was shorter for all worms in each plate. Both the extracts of formulation exhibited anthelmintic activity in dose-dependent manner showing maximum efficacy at $20 \mathrm{mg} / \mathrm{ml}$ concentration.

\section{DISCUSSION}

FTIR plays an eminent role in analysis of plant cell structure and functional group determination where each of the functional group in extract absorb the infrared rays at specific wavelengths and obtain as frequency peak [16]. Phytochemical screening by FTIR showed the presence of flavonoids, tannins, saponin, alkaloids, quinone, and polyphenolic compounds. These phytochemicals can adsorb on cell proteins and disrupt their synthesis which is responsible for paralysis and death of worms [17].

Results on in vitro anthelmintic activity of MCS formulation against earthworm that serves as parasitic model were compared with albendazole as positive control. This drug killed the parasites by interfering with microtubular functions such as glucose uptake and glycogen depletion whereas the phytochemical like steroids alters membrane permeability results in pore formation and eventually causes mortality of parasites [18]. It was observed from the experiment that the combined MCS formulation was much better than the effect produced

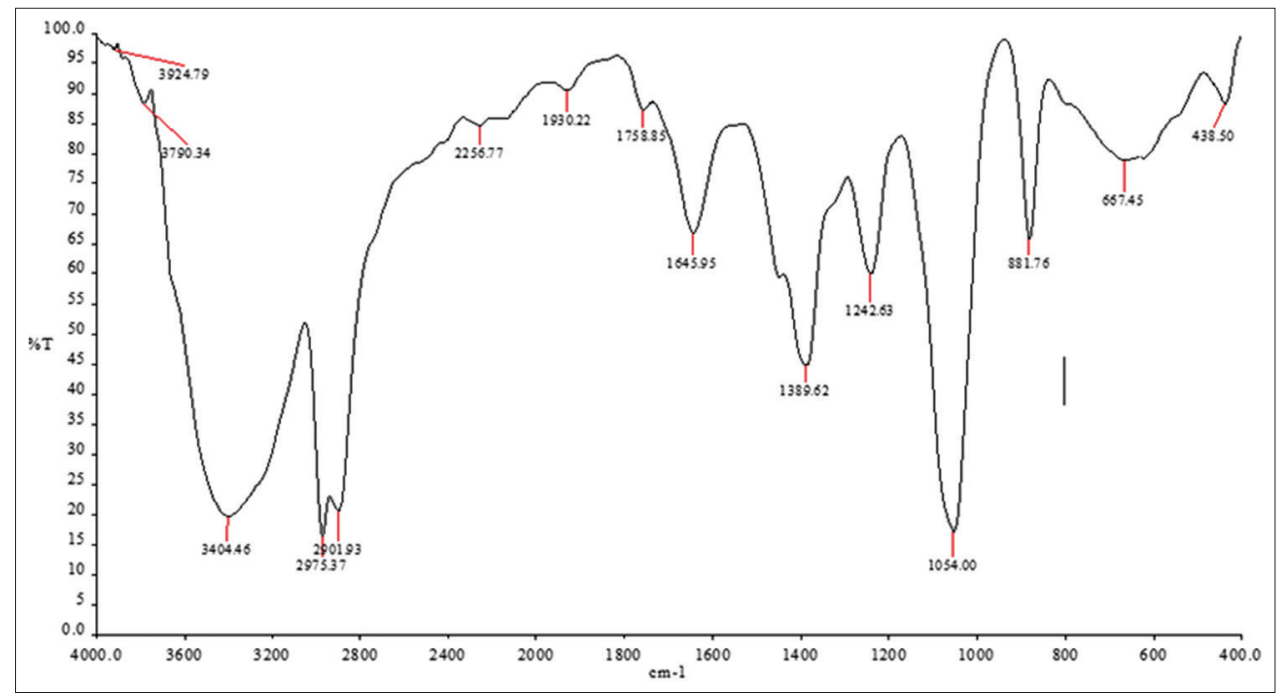

Fig. 1: Fourier transform infrared analysis of MCS formulation 
Table 1: Comparative in vitro anthelmintic activity of MCS formulation in aqueous and methanolic extract

\begin{tabular}{lll}
\hline Group & Concentration (mg/ml) & Paralysis time (min) \\
\hline Positive control & 10 & Death time (min) \\
Aqueous MCS formulation & 20 & $86 \pm 1.35$ \\
& 10 & $75 \pm 0.97$ \\
Methanolic MCS formulation & 20 & $100 \pm 1.57$ \\
& 10 & $85 \pm 0.64$ \\
& 20 & $95.5 \pm 0.76$ \\
\hline
\end{tabular}

Values are mean \pm SEM with $\mathrm{n}=6$. SEM: Standard error of mean

by extract individually. Both the extracts of MCS based formulation demonstrated paralysis as well as death of worms at a time comparable to albendazole at higher concentration. Some phytochemicals such as tannin and phenolic compound were shown to interfere with energy generation in helminth parasites by uncoupling oxidative phosphorylation [19]. Tannins may even responsible to parasitic death by binding to free protein in the GI tract of host animal or glycoprotein on the cuticle of the parasite [20]. Phytochemicals such as polyphenols were shown to have anthelmintic activity against Nippostrongylus brasiliensis [21]. Based on these findings, we can assume that tannins, phenolic compounds, steroids, and flavonoids present in the formulation may be responsible for the anthelmintic activity. Similar to our study, phytochemical screening on morbesi-besi leaf fractions showed all phytochemical content such as alkaloids, flavonoids, glycosides, tannins, saponins, triterpenoids, and steroids [22].

\section{CONCLUSION}

The present study assesses the presence of phytochemicals in MCS based formulation using FTIR and its efficiency in anthelmintic action. Herbal plants are equally effective and potential as synthetic drugs in anthelmintic activity. Both methanolic extract and aqueous extract have the maximum anthelmintic activity. Further studies are essential in finding the bioactive constituents responsible for such activity.

\section{AUTHOR'S CONTRIBUTION}

All authors were equally involved in the manuscript's framework preparation and gathering all necessary information. All authors discussed, drafted, and wrote the manuscript.

\section{CONFLICTS OF INTEREST}

None declared.

\section{REFERENCES}

1. Bethony J, Brooker S, Albonico M, Geiger SM, Loukas A, Diemert D, et al. Soil-transmitted helminth infections: Ascariasis, Trichuriasis, and Hookworm. Lancet 2006;367:1521-32.

2. Stepek G, Buttle DJ, Duce IR, Behnke JM. Human gastrointestinal nematode infections: Are new control methods required? Int J Exp Pathol 2006;87:325-41.

3. Ferreira LE, Castro PM, Chagas AC, Franca SC, Beleboni RO. In vitro anthelmintic activity of aqueous leaf extract of Annona muricata L. (Annonaceae) against Haemonchus contortus from sheep. Exp Parasitol 2013;134:327-32.

4. Roos M. Drug resistance in the sheep nematode parasite haemonchus contortus, mechanisms and clinical perspectives. In: Mayers D, editor. Antimicrobial Drug Resistance. Infectious Disease. Totowa: Humana Press; 2009. p. 1127-32.

5. Taylor MA. A larval development test for the detection of anthelmintic resistance in nematodes of sheep. Res Vet Sci 1990;49:198-202.
6. Shaikh S, Jain V. Development and validation of a RP-HPLC method for the simultaneous determination of curcumin, piperine and camphor in an ayurvedic formulation. Int J Pharm Pharm Sci 2018;10:115-21.

7. Nascimento GG, Locatelli J, Freitas PC, Silva GL. Antibacterial activity of plant extracts and phytochemicals on antibiotic-resistant bacteria. Braz J Microbiol 2000;31:247-56.

8. Vargas-Magaña JJ, Torres-Acosta JF, Aguilar-Caballero AJ, SandovalCastro CA, Hoste H, Chan-Pérez JI. Anthelmintic activity of acetonewater extracts against Haemonchus contortus eggs: Interactions between tannins and other plant secondary compounds. Vet Parasitol 2014;206:322-7.

9. Sasidharan S, Chen Y, Saravanan D, Sundram KM, Latha LY. Extraction, isolation and characterization of bioactive compounds from plants' extracts. Afr J Tradit Complement Altern Med 2011;8:1-10.

10. Poolperm S, Jiraungkoorskul W. An update review on the anthelmintic activity of bitter gourd, Momordica charantia. Pharm Rev 2017;11:31-4.

11. Marie-Magdeleine C, Hoste H, Mahieu M, Varo H, Archimede H. In vitro effects of Cucurbita moschata seed extracts on Haemonchus contortus. Vet Parasitol 2009;161:99-105

12. Kamaraj C, Rahuman AA, Elango G, Bagavan A, Zahir AA. Anthelmintic activity of botanical extracts against sheep gastrointestinal nematodes, Haemonchus contortus. Parasitol Res 2011;109:37-45.

13. Kanojiya D, Shanker D, Sudan V, Jaiswal AK, Parashar R. Anthelmintic activity of Ocimum sanctum leaf extract against ovine gastrointestinal nematodes in India. Res Vet Sci 2015;99:165-70.

14. Tanaka $\mathrm{T}$, Ishida $\mathrm{N}$, Ishimatsu $\mathrm{M}$, Nonaka $\mathrm{G}$, Nishioka I. Tannins and related compounds. CXVI. Six new complex tannins, Guajavins, Psidinins and Psiguavin from the Bark of Psidiumguajava L. Chem Pharm Bull 1992;40:2092-8.

15. Ajaiyeoba EO, Onocha PA, Olarenwaju OT. In vitro anthelmintic properties of Buchholzia coriaceae and gynandropsis gynandra extracts. Pharm Biol 2001;39:217-20.

16. Al-Oqail M, Hassan WH, Ahmad MS, Al-Rehaily AJ. Phytochemical and biological studies of Solanum schimperianum Hochst. Saudi Pharm J 2012;20:371-9.

17. Rashid MM, Ferdous J, Banik S, Islam MR, Uddin AH, Robel FN. Anthelmintic activity of silver-extract nanoparticles synthesized from the combination of silver nanoparticles and $M$. charantia fruit extract. BMC Complement Altern Med 2016;16:242.

18. Hussain A, Sonkar AK, Ahmad MP, Wahab S. In-vitro anthelmintic activity of Coleus aromaticus root in Indian Adult Earthworm. Asian Pac J Trop Dis 2012;2:S425-7.

19. Sreejith M, Kannappan N, Santhiagu A, Mathew AP. Phytochemical, anti-oxidant and anthelmintic activities of various leaf extracts of Flacourtia sepiaria Roxb. Asian Pac J Trop Biomed 2013;3:947-53.

20. Williams AR, Fryganas C, Ramsay A, Mueller-Harvey I, Thamsborg SM. Direct anthelmintic effects of condensed tannins from diverse plant sources against Ascaris suum. PLoS One 2014;9:e97053.

21. Gamenara D, Pandolfi E, Saldana J, Dominguez L, Martinez MM, Seoane G. Nematocidal activity of natural polyphenols from bryophytes and their derivatives. Arzneimittelforsc Hung 2001;51:506-10.

22. Rimta B, Sitorus P, Masfria M. Assessment of physicochemical properties and phytochemical constituents along with antibacterial potential of Tarennapolycarpa leaf fractions. Asian J Pharm Clin Res 2018; 11:78-80. 